\title{
Information, Interactivity, and the Prospects of a Global Citizenry: An Inquiry into the Nature and Function of Online News
}

\author{
Robert MacDougall \\ Emerson College, Boston, MA, USA
}

robert macdougall@emerson.edu

\begin{abstract}
The United States has one of the most technically advanced, most expansive, most evenly distributed, and most freely accessed communication system on the planet. Yet Americans are simultaneously one of the most poorly informed populations (in terms of diversity of opinions/sources, depth and breadth of knowledge, etc.). The proliferation of personalized information services, photo news galleries, computer simulations, and a host of interactive media links on commercial Internet news sites have been hailed recently as one remedy for this troubling statistic. By 2005 the nations comprising Western Europe will represent the largest concentration of netizens in the world with more than 300,000,000 people connected to the Net, many seeking the same conve niences enjoyed by their American counterparts. This paper examines the relationship between technical features and usage patterns on several of the leading Internet news sites. I argue that as the Internet becomes more technically sophisticated, a proportionate, though inverse trend in the epistemological sophistication of its user base will be inevitable. Finally, I discuss the implications this trend holds for the future of a "global citizenry."
\end{abstract}

Keywords : internet, news, information, knowledge, hyper-utilization, decontextualization, epistemological, technological determinism, citizen

\section{Introduction}

The primary aim of this paper is to investigate several significant aspects of a very complex and protracted phenomenon: the popular move away from the printed word to the image. A central claim here is that pictures and images are in fact becoming the primary and preferred means of human symbolization and sense-making. One set of arguments suggest this change is natural enough - with the advancement of communication technology we should expect incremental improvements in communication. A number of commentators (including Negroponte, 1995; Lanham, 1993; and Stephens, 1998) even laud the popular move to the Internet with its graphical interfaces as part of a next step in human evolution.

But such observations, however emphatic, should as yet be granted only the status of open questions. They are questions I hope to shed a bit of light on with some preliminary empirical work. The motivation for this study springs from my own classroom experiences over the past several years at a small (ca.

Material published as part of these proceedings, either on-line or in print, is copyrighted by Informing Science. Permission to make digital or paper copy of part or all of these works for personal or classroom use is granted without fee provided that the copies are not made or distributed for profit or commercial advantage AND that copies 1) bear this notice in full and 2) give the full citation on the first page. It is permissible to abstract these works so long as credit is given. To copy in all other cases or to republish or to post on a server or to redistribute to lists requires specific permission from the publisher at Publisher@InformingScience.org
1800 student) private liberal arts college in Northwestern Pennsylvania, and a much larger (ca. 20,000 student) state university in New York. I was surprised by the lack of what I considered to be key knowledge many students had coming into my classes concerning local and national politics, current events, and international news. What I took to be basic knowledge necessary for essential 
Information, Interactivity, and the Prospects of a Global Citizenry

work in my upper-level mass media course for instance, a majority of students found irrelevant and obscure.

While no direct causal claims associating individual's lack of knowledge of and about certain issues one the one hand, and their use of the Internet on the other, are being made in what follows, I will propose that certain structural features of the Internet, coupled with common Internet usage patterns today may play a role in exacerbating a growing trend of ignorance and/or misapprehension of, and nonparticipation in social, environmental and political issues. The empirical work is discussed, followed by an inquiry into the significance of the data. I'll then turn to reflect upon some of the potential consequences of a popular move toward the Internet as a primary news source, and a concomitant shift toward the image (both still and moving) as the operative informational unit. Before considering the present research, however, a brief history of the theory framing this project is needed.

While popularized by Marshall McLuhan in the late 1960's, the theory of media or technological determinism has deep roots. The idea that a technology (take writing) can exert causal force in a manner that prompts actual changes in the user such that people "give in" to the various structural demands, logics, or representational dictates of the medium was first articulated in a formal way nearly 2500 years ago by Plato in his dialogue The Phaedrus. In that document, Plato - extending some of Socrates' own opinions on the subject - suggests that the steady proliferation of the written word (then manuscripted text) would be accompanied by a progressive bias toward the eyes to acquire information about/from one's world. This would occur at the necessary expense of other senses in Plato's view. Beyo nd that, due to the potential writing has to persist in the visual field, people would inevitably come to rely on the medium as a kind of extension of the mind. The result would be, according to one character in the dialogue, a false sense of knowledge, memory and wisdom - a bold claim by any account.

Jumping ahead to the mid 19th Century with the advent of the Daguerreotype (the first photographic technology) we find some evidence for another key media-determined shift in the human sensorium, and subsequently, in the way individuals make sense of their worlds. The social impact of the image at this time was generally known. Photography was transforming the way people see and interpret the world around them. However, contemporary pundits and publics alike maintained high hopes. Indeed, for an extended period between the Civil War and WWI, the photograph was even considered "legal reality." Early photodocumentarians believed they could represent the world as it was, or "in fact" to the masses. The argument was that people would begin to see the true conditions of existence (in war, famine, poverty, etc) and be moved to action by the images they saw. The expression "seeing is believing" was becoming a kind of truism.

The 20th Century records a series of smaller revolutions in imaging technology: from silver nitrate film emulsion to motion picture film and cinematography; from fixed camera placement to mo vable track and steady-cam systems; from linear analog videotape editing to computer graphic imaging (CGI) and non-linear digital editing. Today we know that practitioners have nearly complete control over the way they want reality to appear. Similar to Plato's critique of writing, then, for taking away our capacity to remember by prompting an over-active, and often inaccurate imagination, we might conceive of modern imaging technology as having taken away our ability to make sense and perhaps also our very need to imagine. The preceding seems to hold if we consider the manner by which these two modes of symbolization - the word and the image - are processed by the human cognitive apparatus.

Today neurologists, cognitive scientists and linguists are in unison when they say that virtually all righthanded, and about $75 \%$ of left-handed people, process linguistic information - the written and spoken word - in the left hemisphere's outer crust (or neocortex), and several regions deeper inside the left side of the brain. "Language, logic, sequence, serial tasks, mathematics, rational argument and other high level functions center around the frontal neo- cortex, some of which is lateralized...other areas in question are, at least, Broca's Area, Wernicke's Area, and the angular gyrus" (Mime, 2003). 
There is good evidence that we use both innate and learned logic and rationality in the language interpretation process (see Chomsky, Piaget, etc). Whatever that ratio we have proven ways of making sense of linguistic statements. We learn a given vocabulary, along with the rules of grammar and punctuation so that when we see or hear a sequence of words we can get to the basic sense, or nonsense, of what's been said. Neil Postman (1985) offers a critique of television based in part upon this argument. Of course, this point would be a good deal more compelling if the image on the television screen did not come with sound. However I don't need to interrogate that issue here since, ultimately, we are talking about the present incorporation of images on the Internet.

The point is that the environment of the word has now moved to the periphery. If the apex of literate culture in the United States was shortly after the turn of the 19th Century, it has been largely usurped at the turn of the 20th by the photo image, the filmic sequence, and the pictographic representation (c.f. Meyrowitz, 1985; Gumpert and Cathcart, 1985; Postman, 1985; Negroponte, 1995; Stephens, 1998). Today there is also common agreement among cognitive researchers concerning the way we process image-based information, where that processing is less rational, or logic-based, and seems to generate activity in the paleopallium or limbic system, and regions concentrated in the right hemisphere; areas generally regarded as the creative and emotional seats. It is interesting to note that, without being aware of the latest research on the topic, Marshall McLuhan opined early on, that "we have not the art to argue with pictures" (1964, p. 231). With the science now behind us, we know that McLuhan may have been making much more of a naturalistic claim than he initially thought.

The latest Nielsen Research data suggests that American children, ages 2-11, watch 3 hours and 15 minutes of television every day. For the past two decades, many psychologists have recommended that parents prohibit children under the age of 2 years from watching any television whatsoever. The argument is that at this crucial stage in brain development the linguistic centers of the brain need to be exercised, and that image processing does not allow for adequate growth in those key areas. (This argument would be a fair bit more compelling if television did not come with sound. Indeed, one might argue that TV has become a kind of superteacher for young children, in that it is cheap, everyone has it, and it provides an ultra-rich stimuli of sight and sound, including language (in fact language of many different voice types, accents, languages, etc). But we don't need to interrogate that possibility here since, ultimately, the current debate centers upon Internet-based imagery which is accompanied far less often by sound.) While McLuhan did not feel he needed this physiological information to make his claims, it does seem to bolster his general position. Having detailed some of the key thinking that informs the media determinist perspective, we are now in a position to consider the empirical portion of this study.

\section{Method and Data Gathering}

In 2000 I began asking students in my 300 level mass media course the following questions: Who is/are/was: Tony Blair, Jacques Chirac, Vicente Fox, Jean Chretien, Fidel Castro, Dick Cheney, Condoleezza Rice, The Zapatistas, Nelson Mandela, Ted Turner, Andy Grove, Your Mayor, etc?, and What is/was: NAFTA, The IRA, The Taliban, Al Qeida, A "Hybrid"; The Euro, etc?, and Where is/was: The District of Columbia, East Timor, Quebec, The Gaza Strip, The Urals, etc. (One version of the questionnaire is included at the end of this paper.) After noticing a pattern of poor scores after the third generation of the class (46 percentile is the current mean at 9 generations), I decided to become more rigo rous in my collection of data. I constructed a short questionnaire designed to provide some insight into how people were using the Internet as a news/information source. Having potentially biased the ind ividuals in my own classes, I forwarded the following six item questionnaire to half a dozen colleagues in the Fall of 2001 who agreed to distribute the questions to their students (via hardcopy or E-mail). That sample qualifies as a convenience pool. Students had the option to forward blank forms to any friends they knew who also reported using the Internet to obtain news/journalistic content. This second tier was a "snowball" sampling, as that group had at least some informal knowledge of the first group. 
Information, Interactivity, and the Prospects of a Global Citizenry

The population that informs this study is made up of sixty college students, with the remainder coming from within several regional businesses (33 persons), and private households (38 persons). My return rate was nearly $40 \%$ for the academic sample, $15 \%$ for the professional/business sample, and $56 \%$ for the household sample. The ages of the total participant pool run the gamut, from 17 years to 79 . While it was clear from the household sampling that some children (the youngest being 6) use the Internet for news-related inquiries, the requisite changes to my IRB proposal to incorporate "minors" has discouraged me from proceeding with that section of the population at this time. However, I remain interested in tracking the usage patterns of these much younger users, as they likely will reveal some interesting realities surrounding the acquisition of the various forms of media literacy that have been described in the literature (especially the seminal work of Gumpert and Cathcart, 1985). The following is a compiled detail of the frequencies and most common answers to the 6 item questionnaire:

Internet News Study Pre-survey:

$\mathrm{N}=131$ (60 students from a private, liberal arts institution; 33 professionals; 38 household users)

1.

How often do you logon to the Internet to seek out news/journalistic information?

$\begin{array}{lllll}1 \mathrm{x} / \text { day }=48 \% & 2 \mathrm{x}=23 \% & 3 \mathrm{x}=21 \% & 5(+) \mathrm{x}=5 \% & 20(+) \mathrm{x}=1 \% \quad \text { Weekly } / \text { Monthly }=2 \%\end{array}$

2.

Provide a list of the topics/issues you typically inquire about (list them in order of importance to you):

Entertainment, sports, weather, foreign affairs, domestic affairs, economy, “just headlines.”

3.

Provide a list of the Internet news sites you regularly visit (list them in order of frequency):

CNN, ESPN, USAToday, NYT, Entertainment Weekly, MSNBC, Weather.com, WashPost,

“Local/Hometown," NPR

4.

Have you set up any personalized news/info services (i.e, "NYT.com,"'“my yahoo," etc)? If so, please list those in order of importance to you:

NYT, MyExcite, MyYahoo, “Local/Hometown,” Mbvies.com, EW.com,

5 .

Which features of the Internet most attract you as a news/info source? (list those in order of importance to you):

Convenient, constantly updated, easy access, picture galleries, "it's free," schoolwork.

6.

What sources of news/info do you typically make use of? Please list those in terms of frequency of use.

TV, Internet, Local/Hometown Papers, Papers (NYT, WSJ, etc), Magazines, Radio.

\section{History Capture, Video Records, Knowledge Quiz, and Interviews}

Additional means of data collection include a history function capture, video records, and informal interviews. In order to track participant's usage of the Internet for news and information purposes I devised a way to capture, via screen shot, the "history" function of the two most standard Internet brows- 
ers (IExplorer and Netscape). This actually required some effort on the part of users, so the return rate was considerably less than the questionnaire. In all only 19 people returned this much more detailed form of information. The directions requested that users return their "captures" on the same day they browsed. Many did, and this allowed me to enter those sites and "walk through" their original visits. A smaller number of individuals allowed me access to the actual machines they use for their daily news. In these cases, a wealth of information can be obtained. For instance, IExplorer allows searches through the history data by site, by most visited, by most visited today, etc. The capture procedure for Netscape's history function requires fewer steps, and generally proved to be much easier for people to obtain and return to me. However, it offers similar information as that made possible via IExplorer.

While I have collected only three sequences of videotaped browsing sessions to date, I plan on obtaining much more of this incredibly rich form of data that allows me to see in "real time" user's navigation through the Internet spaces, and the way they attend to the various forms of content. I was surprised to discover how many people in fact own camcorders of some type (older analog style and/or new digital machines) that will facilitate the process. Here again, I plan on collecting much more of the same.

Users are instructed to set the camcorder up in such a way that it frames their computer's screen. A tripod makes this easy. Otherwise, they can set the camcorder on a desk/table/chair behind them so that it frames the screen from a greater distance (using the zoom feature to adjust the frame size). Whatever the set up, the goal is to get the view in the camcorder viewfinder to be completely filled by the computer screen. Some difficulties seem to arise around reducing glare spots/reflections from surrounding lighting fixtures, sun through windows, etc. I suggested a minimum of 20 minutes worth of video footage of user's news/info-based Internet activity.

My non-academic research participants were also asked to complete and return the post-survey knowledge quiz on an anonymous basis. Less than one half of those who completed the six-item questionnaire from the business/professional sample returned their quizzes, whereas all but a handful of the household users returned completed quizzes. To date I have managed only four interviews with ind ividuals who took the initial six-item questionnaire and knowledge quiz. For that reason, no details from the interviews are included in the study at this time.

\section{A Short Media History: what's in the News}

When Marshall McLuhan suggested that the medium is the message he was making a general point. It was that substantial shifts in the primary medium - like the moves from orality, to writing, to massproduced print, to electronic systems - were the events that most succinctly defined historical epochs and the people who live in them. In short, McLuhan seems to make one big macro-statement about sweeping changes in the way humans make sense of their environments. I'll say he was largely on target, and then add another argument to the mix; one that asks us to look beyond the formal features of a medium, to the content, as something that also needs to be taken seriously.

Earlier, I pointed out a generally accepted truth. It was that at the turn of the $19^{\text {th }}$ Century in the United States we had reached the highest literacy rate per capita. That era also boasted the highest level of political participation. (It is generally accepted that today in the United States we are hovering around our lowest literacy rate (about 20\%) since 1900 (Shapiro, 1992). We now live in one of the lowest moments of political participation, with well under half of all Americans of voting-age going to the polls.) However, these facts likely stem from more than there simply having been an unprecedented number of newspapers and newspaper readers in circulation. Indeed, what's often missed in this story is the attendant fact that, at the time, the press was largely partisan. That is to say, it was overtly biased, opinionated, and explicitly ideological in its reporting. To be sure, the partisan press in the United States at the end of the $19^{\text {th }}$ Century was less concerned with the relaying of brute facts, and more intent upon the exhaustive description of opinions and arguments associated with those facts. The next question is: why 
Information, Interactivity, and the Prospects of a Global Citizenry

did the partisan trend fade? This question prompts us to reconsider the notion of technological determinism as something related to what I'll call hyper- utilization. The term refers to a manic-like overemployment of, and/or preoccupation with, some device or idea. Hyper-utilization implies that there are sensible ways to employ the tools and ideas we have come up with, but also that the calls to consider any range of more reasonable, modest and restrained applications of these things go largely unheard. ${ }^{1}$ Hyper-utilization, in turn, prompts us to consider content.

In the 1880's, when the first powered presses came online there was an almost immediate shift away from the production of papers as the central problem. Indeed, shortly thereafter, the production of readers-qua-consumers becomes the most pressing concern. To reach the broadest numbers and antagonize the least was now the unwritten rule in the newsroom and ad office. News needed to be aesthetic. The new press and yellow journalism are two expressions that entered into industry parlance to refer to the way in which this new method of broadcasting information (the mass produced daily) created a mass audience which, in turn, prompted a new form of writing. Today we have the following popular notions of what news entails (this according to American Heritage): (1) Information about recent events or happenings, especially as reported by newspapers, periodicals, radio, or television; (2) A presentation of such information, as in a newspaper or on a newscast; (3) New information of any kind: The requirement was news to him; (4) Newsworthy material: "a public figure on a scale unimaginable in America; whatever he did was news." This definition itself springs from the Hutchins Commission on Freedom of the Press, which stated in 1947 that a free society needs from its journalists "a truthful, comprehensive and intelligent account of the day's events in a context which gives them meaning" (in Sundar, 1999; $p$. 374).

It is another contingent fact of history that the fact-based, time-sensitive, more objective journa listic style that was born with the telegraph as a necessary way of economically condensing transmissions to manageable levels was later officially codified in newspaper writing. Scientific "objectivity" became the new standard, with a dogged focused on the immediacy of the present. The new writing style deemphasized political discussion and historical context, accenting instead the new and the now. Focusing and fortifying American Heritage's definitions, this new style of news can be generally described as a punctuated sequencing of discrete facts, with less opinionated writing, and a more "watered down," more broadly acceptable kind of content.

Part of this new aesthetic function was the consumptive value publishers demanded from the ir writers. Short news items needed to be understandable in themselves; easy to comprehend after a quick scan, and enjoyable (Schudson, 2003). Gannet's USA Today was perhaps the first newspaper to take this logic to the next level in 1980. As will be discussed shortly, however, a consequence of this change may have been the creation of a less active audience (both in terms of the work they need to do in decoding content, and subsequent actions they may engage in after processing that content). There is little doubt that

\footnotetext{
1 . Americans unquestionably (and often unquestioningly) engage in the hyper-utilization of automobiles, credit cards, and food. There is a push worldwide to engage in the hyper-utilization of the human genome. The last century tells a story of how we have hyper-utilized the image, and we are certainly on course to hyper-utilize the Internet. But in the case of the Internet, we have to add an important criterion to the definition of hyper-utilization: the notion of the sensible. We must take seriously the term "virtual reality." The Internet is a selfdescribed place where we are supposed to be able to participate in activities as if we were participating in them in the real world. For instance, I recently engaged in what I take to be one sensible employment of the Internet. I bought a plane ticket to Finland. This worked pretty much the same way it would have had I called or walked down to my local travel agent (some wider-ranging economic consequences probably notwithstanding). We might say that my use of the net in this case simulated the standard activity. It worked in the cyberworld "as if" I did it in the real world. Practically speaking, I simulated the event. But we'll see shortly that something like the simulation of the firing of a weapon on the Internet is not an accurate simulation in this way. It does not represent things "as if." The moral? We probably shouldn't use the Internet (and the image) for everything - an that list, we may find, probably should not include the present relaying of news.
} 
this trend toward concision is becoming something of a cultural expectation today. It is a kind of hyperutilization. 2

Jumping ahead to the mid 1980's we have record of yet another shift that may be described as a form of hyper-utilization. Ted Turner's Cable News Network begins broadcasting on June 1st, 1981. In similar fashion to the search for readers that was spawned by the powered press, the search for, and even the creation of, news becomes CNN's primary concern. With the 24 hour news service comes the need to fulfill the promise: "all news, all the time." But the public also heeded that promise and soon came to expect just that - new news with every new tuning in. 3

Yet that network's felt need to get the scoop is not their problem alone. The constant expectation or "demand" that developed in the public over the next several years helps spawn the spin doctor during the 1984 presidential election campaign. But this new media personality did not do journalism or news per se; certainly not the fact-based reporting that emerged in the 1920's, and not quite the clear and explicit partisan nature of journalism prior to that. These modern purveyors of "partisanship" wrote, spoke, and discussed in veiled, indirect, and uncertain tropes. Their language was obscured by the manner in which it was designed - via innuendo, esoteric allusion, hyperbole, and oblique reference - not partisan, but also clearly not always objective. 4 What's clear is that by the mid-1980's CNN knew it had to keep talking. Because of the network's unique devotion to news, CNN spokespeople had to fill the new and vast "news hole": that broad space that now existed between one sponsor's paid time and the next.

But we need to be clear about how $\mathrm{CNN}$ is a unique institution when compared to the other major television networks. NBC, ABC, CBS and FOX have a different issue to contend with. Today, given time constraints imposed through commercial dictate and strict profit orientations, network content providers are seldom able to link even the most important stories to the relevant past or to the ebb and flow of social, political and even natural history. Elisia Cohen (2002) offers a detailed analysis of the present market-driven status of journalism in general, and online journalism in particular. Citing McManus' (1994) observation that "viewers and readers are transformed into customers, news into products, and 'circulation or signal areas' into markets," Cohen asserts that "[1]arge ownership interests_-including the relations between media conglomerates (for example cooperative deals between Microsoft and NBC)_constrain news production," (p. 533), and that "[e]ven though mergers were intended to create new efficiencies and synergies, the heavy debt load often imperiled the economic performance of the parent corporations" (Alger, 1998; McManus, 1994 in Cohen, 2002; p. 534). What's more, "increased debt load often meant pressures to dramatically reduce costs, which in turn meant workforce reductions and shrinking news budgets" (Alger, 1998, p. 15, in Cohen, 2002). Cohen's work suggests how, despite

\footnotetext{
${ }^{2}$. It is interesting to note that the introduction of Microsoft's Powerpoint and other visual presentation software has, according to a number of observers, probably accelerated the expectation of concision. Nadine Dolby (2000) has commented upon the way in which the oft-used templates offered in the Powerpoint program tend to "marginalize critical discourse that depends on engagement with language and ideas," and that "the educational profession needs to explore ways to preserve the importance of the word at a time when it is under growing threat." Of course, the threat extends outside of academe, "By their nature," continues Dolby, presentations structured around overheads must lean towards summaries, bullet points, graphs, charts key ideas, and other such truncated written, visual and verbal expression" (p. 1).

3 . This operating logic, with the heavy premium it places on immediacy and "the scoop," seems to be largely responsible for numerous contemporary reporting problems, including the debacle surrounding the 2000 presidential election and the Florida voting miscalls.

4. These qualitative changes are by no means limited to the realm of news. Advertising has moved sequentially over the past 100 years from a focus on the particularities of the product for sale to the vague selling of a life style that is being associated with the product via explicit imagery (the happy crowd inside the automobile, the whimsical walk through the park with Pepsi in hand, etc, etc.). Politics too has undergone a shift in its modus operandi. Media commentators, perhaps beginning with McLuhan, generally point to the first televised presidential debate between Kennedy and Nixon in 1960, as the official beginning of the end of policy-based political campaigning. Henceforth, campaigns move progressively away from content dealing with policy, to an infatuation with the personality of candidates. The argument here is that it is the image that most directly accounts for this qualitative shift, with the visual-based coverage of politics playing the dual roles of initial prompt and continued promulgator of irrelevance and triviality.
} 
the impression of a democratic playing field online, these capital constraints have not loosened with the move to the Internet.

\section{The Economy of the Image}

With speed often of the essence for news producers, what happens to accuracy and new worthiness? 'Increased time pressures on news production result in news routines which may weaken journalists' ability to apply more rigorous and reflective approaches to facticity" (Tuchman, 1978, quoted in Cohen, 2002; p. 543). This, say's Cohen leads to a kind of "Information pollution of the Internet." The ambiguous, open-ended aspect of pictures seems to make them ideally suited to help the time-pressed journalist do their job.

Mirtoff and Bennis (1989) critique the news broadly along these same lines, suggesting how the practical upshot is news content with "no connecting thread, overall context, or historical perspective provided that would help the viewer, reader, audience, etc., make any sense of the larger pattern of ideas, images, etc., assuming that there was one" (p. 50). MIT linguist and social activist Noam Chomsky has pointed repeatedly to the "requirement of concision" as a fundamental problem that greatly reduces the relevance and quality of news today. In a very real sense then, we have returned with greater force to a telegraphic-style (now pictorial) of news reporting at the beginning of the $21^{\text {st }}$ Century for the same reason it existed at the beginning of the $20^{\text {th }}$. There is just no time.

Let's return to television for a moment. If $\mathrm{CNN}$ provides us with obscured interpretation of the facts, the other television network's references to "The New War," "The Showdown in the Gulf," and "The War on Terror" end up being little more than what one media critic has described as news McNuggets (c.f., Deenan, 1991), short, narrow stories embedded between colorful imagery and graphics. ${ }^{5}$ Of course the move to the Internet promised a different kind of news. When CNN invested heavily in an online presence in the mid 1990's they did so thinking that their already vast "news hole" would become virtually bottomless. Today, in fact, this holds true - sort of. My research data to date reveals that, in practice, so many Internet news users barely scratch the surface of the content the mainstream and alternative sites they frequent have to offer.

Supporting McLuhan's claim, then, that "[i]n the name of 'progress', our official culture is striving to force the new media to do the work of the old" (1964; p. 81), Jay Bolter and Richard Grusin, in their book Remediation: Understanding New Media (2000), define the concept of remediation as "the representation of one medium in another." The authors suggest this to be a "defining characteristic of the new digital media." Bolter and Grusin's premise is that all new media take over and re-use existing media. News on the Internet incorporates formal aspects of television and newspapers. For instance, an Internet homepage presents its most important information at "first click" - that is, immediately visible "above the fold," as Bolter and Grusin put it, in the same fashion newspapers are formatted to present to lead stories in the top half of the (folded) front page. The key difference here is that commercial news sites pile on a host of "interactive" media links in their opening pages. Picture galleries, streaming videologs, and computer graphics simulations are widespread. The argument that these features are not merely window dressing around the real/serious news content finds support in my research data. Many respondents explicitly name the photo/picture gallery as one of their preferred modes of news gathering (see item 5 in the questionnaire above).

The Internet and the proliferation of personalized information services, photo news galleries, and computer simulations has been hailed recently as one remedy for the troubling state of affairs we now find

\footnotetext{
5 . Godfrey Hodgson (2000) associates this trend with the end of narratives (what he calls "Grand Narratives") that at least try to make sensible connections between otherwise discrete news items. The consequence, say's Hodgson, is a growing disinterest in news.
} 
ourselves in. Among those who have recognized the problem of ignorance and apathy in the country, and made such positive claims about the Internet, are two US presidents and a host of primary and secondary school administrators. More and more parents, teachers, and politicians are joining the push to integrate the Internet into young peoples' everyday lives. ${ }^{6}$ Unfortunately, while their recognition of the problem is commendable, the remedy they have in mind may be more a prescription for disaster than a cure.

As stated earlier, one reason so many people are excited about the Internet is that it really can promise an almost infinite amount of information. No wonder people interested in the potential educational and research applications of the Internet get so excited. But again the present concern in this study is news, and here again the Internet promises, at least in theory, a bottomless "news hole" (unlike TV, the newspaper, and radio): endless news and information at our fingertips. The problem is an ongoing confusion between theory and practice. Like so many other surveys to date on the topic, my findings show that people want to get their news fast, easily, and on their own time. Therefore, we must consider more fully just what it is people do when on line.

\section{Internet News: in Theory and in Practice}

There is a kind of conceptual disconnect presently between the way we would like to think about our news, and the way we actually go about obtaining it. For instance, my respondents report not spending more than 10 or 15 minutes a day getting their news - whether they get it from the television, which is structurally unable to deliver the appropriate depth, or the Internet, which can deliver but is often unable to do so due to the user's real or perceived time constraints. This leads us back to the issue of hyperutilization. My academic, professional and household samples illustrate this clearly enough. In response to item 5, the question asking respondents to list their favorite features of news on the Internet, the first three most common answers deal with the time-saving issue: "convenience," "constantly updated," and "easy access."

This seems to support my central hypothesis: as the Internet becomes more sophisticated (in technical terms), it's content, practically speaking, will become less sophisticated (in epistemological terms). Users across the board report being interested in getting in and out of Internetsites quickly. It is little surprise, then, that the fourth most common aspect of my respondent's favorite news sites are the imageoriented features (like USA Today's "Day in Pictures," and "Photo Gallery," The New York Time's "Interactive Feature" or CNN's "Graphics" links.). But let us be finally clear about the distinction I am drawing between what is structurally possible, and what is bearing out in practice. That the Internet may contain all of the information necessary to build knowledge structures that can potentially solve most or all of the world's pressing problems in not enough in and of itself. This point holds for any kind of database, whether it's made of papyrus or electrons: information can do nothing if it remains untapped.

\section{Autonomy and Intention Online}

What, then, can we say of the power of the online news consumer to acquire or produce new knowledge or build upon knowledge they already have? Elisia Cohen (2002) argues that "market-driven journalism in any form gives little power to consumers to influence the news market... [e]xamining the relationship between news producers and the consumer is important given the greater control, choice and selection processes available with media today. A crucial tenet of market-driven journalism is that consumers are not empowered to act in the rational pursuit of self-interest"(Webster and Phelan, 1997, in Cohen, 2002; p. 536). I interpret these authors as referring to a kind of pseudo-autonomy or soft-determinism charac-

${ }^{6}$. See MacDougall $(2001$, p. 253) for a partial account of the lauding that has accumulated around the Internet. 
Information, Interactivity, and the Prospects of a Global Citizenry

terizing the situation for so many users online. She continues, " $[\mathrm{t}]$ he desires individuals bring to the market may be the products of choices the market already offers, and the impacts of communities of taste, peer groups, and other external forces" (McManus, cited in Cohen, 2002).

News conglomerates may actually end up having more power on the Internet according to Cohen. "The influence of media conglomerates on news production functions in much the same way as in traditional media, if not more so (for example, Disney owns Go.com), which serves as ABC.com's search engine framing every news story. (Cohen, 2002; p. 537). ${ }^{7}$ Thus, “[a]udience patterns and rationales for news consumption choices appear less certain than with older media” (ibid). In other words, what's on offer due to domain constraints, cannot include links to the BBC online, or NPR.org (two of the more rigorous news outlets by many accounts). Cohen continues to explain what often happens in the context of a time-pressed user looking for news online: “[w]hen journalistic quality is difficult to discern, consumers are compelled to rely on "brand names" or develop alternative information sources for evaluating news, such as direct civic involvement" (ibid).

While I did not ask my respondents about their individual civic participation, most did tend to cite the mainstream/brand names Cohen mentions in her article: USA Today, MSNBC, CNN, etc. The result is that so many users end up tapping into the news product of what Cohen calls "Oligopolistic 'pack' reporting." But again, allowing Negroponte (1995) some room here, is there more news choice online? In theory the answer is yes. However, without belaboring the point, the present study seeks to move beyond the realm of theory. In practice then, how does it work? If the Internet provides us with the potential of a "bottomless news hole," it is rarely being filled by mainstream news producers, nor dug into by consumers/users. Next, let's consider a crucial distinction.

\section{Knowledge and Information}

The first three entries in The American Heritage Dictionary of the English Language, $4^{\text {th }} \mathrm{ed}$. for the term Knowledge are: (1) The state or fact of knowing; (2) Familiarity, awareness, or understanding gained through experience or study; (3) The sum or range of what has been perceived, discovered, or learned. Consider next the same source's entries for Information: (1) Knowledge derived from study, experience, or instruction; (2) Knowledge of specific events or situations that has been gathered or received by communication; intelligence or news; (3) A collection of facts or data: statistical information.

It is interesting (if also disturbing) to note that aside from the third entry under Information, the two words are considered virtually synonymous. It seems that proponents of the Internet listed earlier from PTA members to presidents - have accepted this conflation. However, if the editors of news age ncies choose to include the punctuated tidbits that are common in many of the nation's most popular dailies and TV news specials on their Internet spaces, then news and information remains just that - unprocessed (even unprocessable) raw material. This may be especially the case where picture galleries, short video segments and computer simulations are the preferred content (both from the producer's and the consumer's vantage). I've already detailed some of the arguments for why pictographic information is less amenable to sense-making processes. And yet another phenomenon may be at work.

\footnotetext{
7. This is the same way "sites such as CNN.com list 'related stories,' the stories presented by the Internet page typically are those within the framework of CNN.com and its associated (Pathfinder) Internet sites" (Cohen, 2002; p. 538). The argument here is that "centralized" means "constrained." CNN will not point you beyond CNN's domain. This fact is attendant to my discussion of decontextiualization and constraint that follows later in the paper.
} 


\section{Media Literacy as "Nurtured” Skill}

Gumpert and Cathcart's (1985) notion of the media generation should also be taken seriously. These theorists contend that: (1) there is a set of codes and conventions integral to each medium; (2) such codes and conventions constitute part of our media consciousness; (3) the information processing made possible through these various grammars influence our perceptions and values; and (4) the order of acquisition of media literacy produces a particular world perspective which relates and separates persons accordingly.

Extending Gumpert and Cathcart's argument, I'll suggest that the world perspectives fostered by immersion in a primarily visual symbolic environment results in a less coherent, less critical, and ultimately less knowledgeable population. ${ }^{8}$ The author's fourth point is particularly crucial to the idea of a "media generation" or "cohort" as that is an important idea in terms of this study. One thing that was abundantly clear in the questio nnaire data is that the college students (those most apt to fall within the television/image and computer/iconic literate generations as having been born in the early to mid 1980's) were somewhat more apt to visit and bookmark sites that put a lot of energy into their "interactive" and pictographic content. ${ }^{9}$ Gumpert and Cathcart would suggest that the attractiveness and familiarity of the image links is what allows these younger users to stay within the limits of their shortened attention spans or "twitch times." But to say that this is how a generation (or two) have adapted to the new media environment is to say nothing of the way things naturally ought to be. Yet, there are commentators who try to push the naturalistic argument. For instance, Richard La nham (in Stephens, 1998) say's our eyes were selected over millions of years of evolution as the dominant, most valuable sense. But this statement can be dispatched straight away, as it ignores the reality that the human visual apparatus ends up being a relatively feeble sense modality when compared to that of so many other terrestrial species (most notably, feline and avian). No, our eyes have not been our strong suit as of late. Yet despite any arguments over our physiology, what we can say with some certainty is that the world of news today is one dictated on the whole by a kind of attention economy that centers upon visual catchy-ness, sound bites, and brand recognition. 10

My second hypothesis is really, then, just a logical extension of my first: that there will tend to be an inversely proportional trend in the relationship between the technical sophistication of the Internet's user base (how technologically saavy there are), and the epistemological sophistication of the knowledge those users obtain and integrate into their respective lifeworlds. Here is another point at which McLuhan may have seriously misinterpreted the possibilities of computer technology. He probably did not take seriously enough the impact of certain kinds of content when he said things like "[i]n an electronic information environment, minority groups can no longer be contained or ignored. Too many people know too much about each other. Our new environment compels commitment and participation. We

\footnotetext{
8. While the people, places and things included in the "knowledge" quiz administered to respondents after they returned the 6 item questionnaire is largely an arbitrary list of discrete nouns, the paltry scores indicate that many individuals possess a frightful lack of understanding concerning not only the brute definitions and descriptions, but also the relationships and significances of things that in fact relate centrally to their positions as students, citizens, voters, earthlings, etc.

9 . References to The Onion, NPR, Reuters and other news sites that typically feature more lengthy, text -based news stories, came low on all of my respondent's lists (I'll admit, however, that a larger, more random sampling may muddy this current finding).

${ }^{10}$. Cohen (2002) provides an exhaustive account of Internet content designed with "profitability of public attention in mind." (p. 535). Cohen continues, "[r]ecent research also confirms that online news viewing is increasingly concentrated on name brands known from television, or print" (Pew Research Center, 2000, in Cohen, 2002; p. 535). It is Cohen's claim that "the online commercial news environment increases market pressures at all levels, because news production occurs faster, competition is fiercer, the branding issues are tougher to establish, and media consolidations are what have defined the new media environment" (Cohen, 2002; p. 537). So, how does this market logic manifest itself online? More color, more pictures, more sound, more video segments above the fold. In short, more "interactivity" (as described herein).
} 
Information, Interactivity, and the Prospects of a Global Citizenry

have become irrevocably involved with, and responsible for, each other" (1964, p. 24). This insight simply has not borne out. The decontextualized nature of so much of the news users grab from the Internet today has not yet resulted in a more informed, more knowledgeable, more aware, or more participatory person/citizen.

We can see an almost monomaniacal form of hyper-utilization at work. Throughout most of the 1990's Internet users were very often given the option of choosing the "text-only" or "frames" version of a Internet site. This is rarely the case today. The result is that anyone using hardware and software much more than five years old is precluded from entry onto the information-superhighway. The text-only option was a hold-over designed to accommodate the text-based DOS browsers (like the original Gopher program) that did not support any graphical content. In keeping with the argument set forth earlier in this paper that is sustained by Eisenstein (1979), McLuhan (1962), Postman (1985, 1992), these less technically sophisticated text-based systems were the only real guarantors of more sophisticated content (in terms of depth and breadth of information, diversity of sources, etc). The fast-shrinking collection of text-based sites do not require the latest processors, software or connection speeds. Of the text-only sites that remian, most can still be accessed and navigated efficiently with a 386 machine running through a $14.4 \mathrm{~K}$ BPS modem in DOS mode.

Literally thousands of text-only news/information-oriented Internet sites do still exist, but such an approach is now considered substandard from both technical and marketing perspectives. No "serious" news server can hope to respectfully operate in this manner today. Therefore, as more of us go online, more of us will unscrupulously put ourselves into a position of trading knowledge for information. It is reasonable to suggest, then, that we are moving to a more passive kind of "knowledge acquisition" that is more akin to brute form of information gathering. Info-mania and info-tropism are surely contemporary ailments. As Plato might contend, they should not be confused with knowledge acquisition or learning. Regarding McLuhan's point about the potential for increased and irresistible participation, what many perceive as interactivity is more likely a veiled new form of passivity.

\section{What Interactivity is}

Chan Olmsted and Park (2000) use the term "sociability" to ostensibly describe the interactive structures built into Internet news sites. These include: e-mail click throughs, news tips forms, live camera views, counters, animations, push technology, video streaming, and help and search systems. This kind of "passive activity" is most obvious in the increasing use of personalized news services that send along items based upon a key word search. Predicated upon the idea that events in the world are quite clearly delineated/earmarked as certain kinds of news with clear descriptions and associations, these systems deny users participation in the association/sense-making process insofar as they are not allowed to make those active, and often sensible yet subtle connections and relationships between what appear to be discrete occurrences in, for instance, "economics," "foreign affairs" and "the environment." To be sure, an argument could be made that today the status of Walmart stock is intrinsically linked to our nation's national security. ${ }^{11}$ This illusion of interactivity may become one of the key findings in my research. To be sure, true interactivity on mainstream sites is difficult to enact, and often harder to find. It may be surprising to discover that if you type an out-of-domain Internet site or chatroom on a mainstream site, you will be thrown off the local server. "For example, viewers will be 'ejected' from the [MSNBC chat] rooms" (Cohen, 2002, p. 540).

Closely associated with this pseudo-interactivity is the threat of homogenization. This is also indicated in my research data (see especially items 2 and 3 above). With the mainstream news agencies offering

\footnotetext{
11. One needn't go into the intimate relationships that seem to naturally exist today between things like automobile sales, oil production, gasoline prices, foreign aid, famine, poverty, terrorism and war.
} 
the "best" (very often meaning simply the most technically sophisticated) news, and given the points already made concerning both producer's and users' valuation of content, we may find that the Internet fosters a hidden homogeneity. In his book Interface Culture, Steven Johnson describes how the Internet is becoming populated by what he calls "intelligent agents" (1997, p. 188). Like the software that anticipates our search needs, this kind of push technology did not end up proving itself efficient enough in the realm of Internet marketing where it was originally tested. Yet the feeling most of my respondents have expressed - that they are getting access to a great deal of information in a very short amount of time - holds true. This of course prompts us to recall the distinction made earlier between information and knowledge. Despite popular opinion on the matter, they are not the same.

Johnson (1997) recognizes the positive potential the Internet represents. He envisions a structure of news and information that would be regularly created by news corporations and less centralized news services alike. This would be akin he say's, to the way musical tastes evolve: from the traditional/topdown tendency, that is a one-to-many pattern of corporate and mainstream content, to the more mature bottom- up tendency that results in thorough knowledge of the anti-establishment, the subcultural, the independent source, the many-to-many (pp. 200-204). But Johnson's vision may be little more than fancy given the premium users seem to place on time pressures. Certainly the process Johnson describes would require people to tap into many of those text-only sites and newsgroups or at least dig much deeper into the mainstream sites, (both activities that necessitate a considerable amount of reading).

Unfortunately, Johnson's top-down story may accurately describe so many Internet news user's experience today. While he was making a comparison to the way people's tastes in music change, he does an uncanny job of describing how, when people bookmark or set up personal accounts on mainstream news sites like CNN, Yahoo, MSNBC, USAToday, etc., they tap into top-down systems that dole the "same old favorites, dictating that everyone attend to a smaller, more predictable repertoire" (1997, p. 204). What Johnson calls "predictable repertoire," others have called "received truths," and "conventional truths" (Herman and Chomsky, 1988); "Half-Truths" (Chomsky, 2001); and "shriveled and absurd" content (Postman, 1985). The connection we can draw between Johnson's musical metaphor and the mainstream news site is uncanny. Less diversity, and a homogenizing, even homophilic tendency is a clear result. Again, this all runs counter to the structural possibilities inherent to the Internet. But we can no longer talk only of theory. The problem is that, in practice, research and the comparison of news sources requires work (work people don't think they need to invest) and time (that people claim not to have).

\section{Some Philosophical Implications}

The progressive move from the word to the image that McLuhan's brand of technological determinism entails, and the notion of hyper-utilization come together with market logic and user preference to account for the trends described in this paper. The entire process, it would seem, is now largely out of rational/intentional control. It is a self-prodding system. Internet designers are compelled to keep pace with the technical capacities of the technology. This is why we will continue to see the Internet pushing the limits of speed and vision. But many hasty assumptions are also being made about the rationality of Internet news users/consumers. As Chan-Olmstead and Park (2000) suggest in their analysis of Internet news site designs, a great deal of design work is predicated on the supposition that an audience is active and goal oriented. This simply may not be the case. With the ever-widening convenience of access to fast Internet connections today, and their relative ease of use, we may be seeing a heightened number of Internet news users who behave more like the non-discriminate TV news viewer ( as opposed to the somewhat more discretionary print news reader).

With respect to convenience and accessibility, Stephens (1998) suggests how "images are marvelous ly accessible...we take advantage of the accessibility of images to aid those who may not understand a par- 
Information, Interactivity, and the Prospects of a Global Citizenry

ticular language - visitors to the Olympics, perhaps, or any space aliens who happen upon Pioneer 10 [referring to the platinum engraving affixed to the spacecraft's hull]" (p. 10). The problem with that assessment in my view is the way Stephens ignores the essence of the problem. And that is that we are not talking about the task of directing Ukranian tourist to the rest room, or giving space aliens some general idea of who and where we are in the universe. No, the ideal task of images in the news today should be to give people a clear, grounded, unbiased, contextualized understanding of what is going on in the world around them. The problem, of course, is that images may be structurally unable to deliver.

Yet journalistic ethic and consumer need may be moot. We are moving toward a sensory-immersive environment centering upon image and sound that is in part due to an implicit business agreement between Bill Gates of Microsoft, and Andy Grove of Intel Corporation. These macro-level realities must be part of the discussion. While we could argue about the chicken and the egg on this, I'll punctuate the sequence arbitrarily and say the when Grove brings to market a new 2-Gig processor, Gates reorients to the production of new, updated, and "improved" software that utilizes all of that processing power and new bandwidth capacity that processing power entails. ${ }^{12}$ As Gates brings to market the latest powerconsuming operating systems, office suites, Internet browsers and media players, Groves is compelled to develop a chip that allows for the next innovation in software. This in turn allows Gates room to add more color, sound and "interactive" capacity to his products, which prompts Groves to perfect the newer 2.5 or 3.5-Gig device, etc, etc, etc.

So if one accepts the argument concerning the difference between words and images offered throughout this paper, then it is sensible to think that, as the technology progresses (with progression being determined almost exclusively by bandwidth ${ }^{13}$ capacity today), the usable ${ }^{14}$ content of Internet news sites will degrade proportio nately. Will the content of users' heads necessarily follow? The next several decades will surely provide an answer.

Next, I should say something about the prospect of interactivity in the context of human isolation. As far as Plato, Innis, and McLuhan were concerned, the exteriorization of knowledge brought on by writing (and later extended by the printing press) was, in effect, decontextualizing, alienating and antihuman. If we are the embodied creatures that these theorists imply, then all extant communication media, by definition, separate us from that embodiment and direct experience. Ad vertisements for personal computers, personal digital assistants, and personalized news services illustrate the popular trend toward individuation.

As noted earlier, all communication media/technologies have been alleged to carry demand characteristics (specific logics and grammars) which exert causal forces that can impact and change the perceptions, attitudes, beliefs and behaviors of individuals and, potentially, entire populations. Ong (1982) implied an extension of the work of Eisenstein (1979), Innis (1951), McLuhan (1962), and others to consider the determining influences previously associated with text, into the realm of modern communication technology. He suggests that "[ $\mathrm{t}]$ he sequential processing and spatializing of the word, initiated by writing and raised to a new order of intensity by print, is further intensified by the computer, which maximizes commitment of the word to space and to (electronic) local motion and optimizes analytic sequentiality by making it virtually instantaneous" (Ong, 1982; p. 136).

\footnotetext{
12. The note of cynicism in this last statement is intentional. The discontent surrounding the constantly updated Windows operating system is, at this point, a kind of cultural lore.

13. As broadband technology continues to grow, real-time and downloadable video over the Internet (i.e. Internet Video) will improve in quality and speed" (Chan-Olmsted and Park, 2000; p. 321).

14. Here again, I idealize. By usable I invoke something like the Hutchins Commission's criteria for "news": a truthful, comprehensive and intelligent account of the day's events in a context which gives them meaning. So, having recounted the ideals journalists held for themselves early on. And given the state of things in the world today, I think my call for a more ideal news situation online is warranted.
} 
Ong was writing before the graphical interface was invented. He mentions the computer here only in relation to its representation of the word, yet his point concerning decontextualization gains even more relevance when we consider the swiftly accelerating proliferation of graphically interfaced (i.e., iconic or image-based) electronic media today, and the manner in which that proliferation is predicated on the logic of providing individual users with singular control of their machines. In short, as more and more people get on- line, more move into the kind of individualistic, decontextualized perceptual and experiential mode Ong describes. Put another way, the computer renders nearly meaningless the constraints of time and space such that we, the individual users of electronic media today are, as Joshua Meyrowitz explains "all alone together," and "everywhere at once, but no place in particular" (1985).

Consider as well the increasing presence of CGI animation on many of the mainstream Internet news sites. Taking Ong's and Meyrowitz's lead, we might say for instance that War is relatively easy to separate from its context. The contention here is that this may be the case because war has become so easy to IMAGEine. Peter Jennings, the long-time ABC news anchor, cynically commented during U.S. military operations over Kosovo on the fact that with the Internet he could now go to CNN.com any time he felt the urge, and watch a computer-simulated model of a cruise missile firing. The problem, explained Jennings, is that computer-generated cruise missiles always hit their targets. Perhaps Jennings maligned $\mathrm{CNN}$ for misrepresenting the truth of the matter because he feels the squeeze of lost ratings. Perhaps he doesn't like computers. Whatever the case, his observation holds significance for the present study: digitized cruise missiles aren't real.

Of course we are not talking about getting down to some Platonic Truth. Objectivity in news is a myth surely. The trick with the Internet will be how to get people to think for the mselves - and this should not mean isolating people. ${ }^{15}$ The fact of the matter is that we do not tend to share the keyboard in the same way they share the sofa. The personal computer, more often than not, remains just that: a private device. Hypnosis is always easier when one is alone with the magician. Like Plato's prisoners, ${ }^{16}$ who cannot see others even though they are sitting beside them, the Internet news seeker rarely truly interacts - despite much talk of interactivity online. Psychological isolation, then, may be particularly dangerous when it comes to making sense of news increasingly relayed in pictographic form for at least three reasons: emotional bias, polysemy, and decontextualization.

Mitchell Stephens (1998) cites the Medieval philosopher Thomas Acquinas, who noted how images in churches and other places of worship could be used to excite the emotions, which tend to respond more directly to things seen than by things heard. Acquinas' point doesn't need much in the way of argument to be convincing. He neuro-physical facts, and our own experience support this claim. A photograph of a breath-taking landscape - or a horrible scene of war-time carnage for that matter - often does more to

\footnotetext{
15. Mitchell Stephens provides us with more ironies when he tries to make a case for the ability to judge earnestness and thoughtfulness via a television screen. The case in question is an effort by Stephens to show an irony in author William McKibben's own actions - where the self-described anti-television techno-phobe appears on a talk show to promote his book). Stephens cites the New Republic's Robert Wright, who "admitted that McKibben looked more 'earnest and thoughtful' than he had expected from reading reviews of his book" (Stephens, 1998; p. 63). But the irony gets deeper with Stephens' use of Wright here. "TV has won for his [McKibben's] cause one small battle that his book alone couldn't have won," Wright observed, "both because I don't have time to read it and because it is missing some kinds of information (some very "natural' kinds of information, like how a person looks when saying what he believes...)" (ibid). This is a puzzling statement that Stephens seems to endorse. As if people can't "make a face" for the camera? One of the more solid conclusions in social scientific research today is that people can deceive with marked success if they simply want to, and that the presence of multiple feedback channels (like those existing during a face to face exchange), often do more to aid the would-be deceiver, than the recipient of the message. What's more, decontextualizing the interaction through televisual mediation even tends to aid the sender/would-be deceiver (see for instance the work on deception by Burgoon, and Buller and Burgoon). This is not to probe the significance of Wright's admission that he had no time to read McKibben's work. In short, that we live busy lives should not give us license to gloss texts we are trying to argue against/for.
}

16. The reference here is to the "Allegory of the Cave," a dialogue intended to generate reflection upon the nature of knowledge and education found in Plato's Republic. 
Information, Interactivity, and the Prospects of a Global Citizenry

immediately "stir the soul" than an essay describing either one. The problem, as Stephens actually suggests, is that it becomes "necessary to rely on the most obvious of images, on cliches: a skull and crossbones, for instance, or a father snuggled up with a book and a child" (Stephens, p. 61; 1998). Stephens goes on to cite the French semiotician Roland Barthes, who "gave the example of the use of a bookcase in the background of a photograph to show that a person is an intellectual. Such an image has a wide set of possible meanings. It is polysemic. "As a result," say's Stephens, "as images that try to convey meaning without the use of words become less ambiguous, they also become less interesting, less challenging and vice versa" (ibid, p. 67). ${ }^{17}$ But the polysemic aspect of images may have more to do with the way humans process them, as opposed to any intrinsic qualities of the images themselves. Robert Zajonc has "long argued for the primacy of affect, by empirically demonstrating that emotional reactions can be independent of - and/or precede - cognitive appraisals of incoming stimuli (in Sundar, 1999; $\mathrm{p}$. 380). Where images are concerned this point may be almost rule-like.

C.A. Bowers (2000) considers in detail the problem of isolation and decontextualization that characterizes a great deal of digital communication today. "There is an emphasis," say's Bowers, "on diagnosing problems and framing solutions as models that can be replicated in various cultural contexts" (p. 75). This statement, along with Jennings' comments about fantastic content on CNN.com suggests that we have now entered a time when news can be what, when, and wherever we would like it to be. While talking specifically about computer technology's impact on ecology, Bowers' point that such decontextualized, reductionist "forms of knowledge are inadequate to rectify the problem of moral blindness" and "ignorance of the larger circuit" holds sway in other areas (ibid). Clearly, Jennings' remarks concerning US weapon systems in action demonstrates how computer image processing can practically nullify the real-world significance of war.

In keeping with Bower's assessment, images may be more accurately conceived as an often decontext ualized, constrained discourse that prompts a fetishization both of the object and subject - in the case of Jenning's example the object is a cruise missile, and the subject War. This is related to an ironic point Mitchell Stephens makes about another "strength" of images - namely, their concision. Where images afford "a significant advantage for drivers speeding by, or on a crowded computer screen” (1998, p. 61-2). Stephens, presumably, is making reference to a traffic sign, or an iconic representation on a computer "desk top." It is notable that these examples suggest a hurried interaction (the first) and a confusing environment (the second). With the preceding discussion of emotional bias, polysemy and decontexualization, I have indicated why the use of images will not assuage the problem that is our rushed and crowded lives. ${ }^{18}$

\footnotetext{
17 . Umberto Eco referred to this as the "fatal polysemy of images." We can begin to understand Eco's point most succinctly perhaps, by again considering the image of war-time carnage. The image of a dead Afghani with a fatal gunshot wound to the head could, depending on the specifics of the viewer, mean very different things. For a one person it could signal the folly of American foreign policy; for another, the success of American military efforts - and a well-deserved come-uppance for the dead man. Yet part of the problem with either interpretation may be the absence of important details to help frame the image.

${ }^{18}$ To this Stephens (1998) makes some telling remarks about the quantitative advantages of images. Moving images, say’s Stephens, do "manage to impart a remarkable amount of information and impressions in a short period of time." He continues, asserting that "images have the potential to communicate as least as efficiently and effectively as printed words" (p.5). Unfortunately, I have no idea what that last clause might possibly mean. What is clear is that Stephens sees that images as able to impart a greater amount of information. With another dig at the author Bill McKibben, Stephens offer this: "if the measure is direct stimulation to our senses, a page of print makes a few moments of television look like a five course French meal" (p. 67). While it's ironic that Stephens chooses French cuisine (among the lightest and most aesthetically oriented in the world) as his metaphor, that comparison also makes the explicit point that television is more about appearances, not phenomenal experiences. In short TV looks like this or that - it is not those things (granted the same can be said of print - yet there is less presumption surrounding print in this respect.
} 


\section{Conclusion}

So, while most communication/media scholars have positively rejected Shannon and Weaver's communication model, the general public and many popular commentators seem far behind. This is despite the fact that fairly sophisticated digital image processing technology is now finding its way into the consumer's hand ( $\$ 300$ can buy a 2 megapixel camera and processing software that delivers impressive results). Do you know what you can do with your camera and Adobe Photoshop? Despite this. so many people still equate the photographic image with reality today - as they did around the year 1900. Are we hard-wired in this way or is this a learned valuation? Whatever the answer to that question, now more than ever, with 3-D imaging, streaming video, and CGI all coming into their own on Internet news sites, we need to stop thinking about communication media as neutral vehicles that we use to transfer information, thoughts, and ideas. Especially in this age of the image, we need to start thinking about communication as occasions for people and institutions to create identities, ideologies, and wholly fantastic realities.

Finally, I promised to discuss some of the potential implications these trends hold for the future of a global citizenry. We know that McLuhan himself held high hopes for the Global Village. If France, England, Germany and the other nations making up the European Union have maintained high journalistic standards to this point, the prediction here is that as the EU moves from the biting satirical news programs found on Canal+, and France 2 (like the always provocative Campus), and the thoughtful content that was only available five years ago via Minitel (in France at least) the future of the global citizen looks bleak. Will the move to the image that seems built into Internet-based news today spawn a new generation of whimsical, unreflective, easily swayed individuals? Will we move slowly back to a kind of oral culture with the hypnotic effect of the "village elder" (the news anchor) dictating meaning and truth? Will the secondary orality that began with the telegraph coming into its own with the Internet image gallery and the power of first impression? Or, will all this imagery snap us out of our collective reverie and create a population of cynical, skeptical, and perhaps then careful assessors of news and information?

There is no question that the medium theoretic perspective tends to ignore many of the novel and creative ways in which users employ their medium of choice toward emancipatory ends (see Boczkowski, 1999; 2000). Clearly, many studies of electronic media use spanning the last twenty years have ignored or overlooked the positive practical implications these employments can hold for users themselves. 19 On that note, I'll add that this is not an argument about high or low culture. Rather, it's about the possibilities of truly broadcasting the kind of information that allows for the generation of knowledge that is usable in creating and maintaining a democratic situation and the open market place of ideas that same situation requires. This is a notion itself integral to the idea that news "is supposed to give us information in order to function more effectively in a complex world" (Mitroff and Beniss, 1989; p. 10).

Having said that, some are discouraged to learn that many people now consider the self-referential metacommentary of Entertainment Weekly (see EW.com) to be the important, pressing news of the day. But again, while cultural critics submit that there is no accounting for the public's taste, the story may not be a simple matter of personal choice. As stated at the very beginning of this paper, multiple, powerful forces seem to be at work. Their extent and ultimate consequence remain to be seen.

\footnotetext{
19. For the negative account see in particular, Culnan and Markus, 1987; DeSanctis and Gallupe, 1987; Kiesler, Siegel, and McGuire, 1984; Sproull and Kiesler, 1986. For a collection of more charitable stories see Bench-Capon and McEnery (1989), Boczkowski (1999), Coats and Vlaeminke (1987), Feenberg (1993), Furlong (1989), Guldner and Swensen (1995), Jackson (1996), Kerr and Hiltz (1982), Lea, O'Shea and Fung (1995), Lea and Spears (1995), Meyers (1987), Rice (1987), Rice and Love (1987), and Walther (1992, 1993, 1994, and 1996).
} 
Information, Interactivity, and the Prospects of a Global Citizenry

In the end we must admit that a complicated synergy of factors are at play, including (1) the news industry's commercial imperatives toward concision and consume-ability or "user-friendliness;" (2) the media-deterministic logic associated with the move from the word to the image and the associated tendency away from systematic, rational thought; and (3) user's preferences: the continued American/WesternIndustrial turn toward the valuation of entertainment, speed, quantity, convenience, efficiency, ease of use, etc. No doubt all three seem to contribute to the process of hyper-utilization of news online described herein. As far as a final prognosis is concerned, the cynic in me suggests that as we get online we can't help but fall headlong back into Plato's cave - a place full of isolated ignoramuses making much ado about no thing in particular. Is it all we can do to wait and see? Better yet, it seems high time "to reconsider the types of news judgements, news routines, and skills required to attend to the new media environment" that is the Internet (Cohen, 2002).

\section{References}

Alger, D. (1998). Megamedia: how giant corporations dominate mass media, distort competition, and endanger democracy. New York: Roman and Littlefield.

Boczkowski, P.J. (1999). Understanding the Development of online Newspapers: Using computer-mediated communication theorizing to study internet publishing. In New Media \& Society, 1, 101-126.

Boczkowski, P.J. (2000). Distribute and Conquer? Changing regimes of information creation in online newspapers. Paper presented at the annual meeting of the International Communication Association, Acapulco, Mexico.

Bolter, J. David and Grusin, Richard (1999). Remediation: understanding new media. Cambridge, MA: MIT Press.

Bowers, C. A. (2000). Let them eat Data: how computers affect education, cultural diversity, and the prospects of ecological sustainability. Athens: University of Georgia Press.

Chan-Olmsted and Park (2000). From On-Air to Online World: Examining the Structures of Broadcast TV Stations' Internet Sites. In Journalism and Mass Communication Quarterly. Vol. 77, No. 2; Summer, pp. 321-329.

Chomsky, Noam (2001). 9-11. New York: Seven Stories Press.

Cohen, Elisia, L. (2002). Online Journalism as Market-Driven Journalism. In Journal of Broadcasting \& Electronic Media. December, 46(4), pp. 532-548.

Deenan, Sally (1991). Doing the Boca: an interim report from a reinvented newspaper. Columbia Journalism Review. May/June.

Dolby, Nadine (2000). The Tyranny of the Overhead: the conference paper reconsidered. Teachers College Record. Date Published: 4/5/00. Located at http://www.tcrecord.org (ID Number: 10515, Date Accessed: 6/21/00).

Eisenstein, E. (1979). The printing press as an agent of change: Communications and cultural transformations in earlymodern Europe. New York: Cambridge University Press.

Gumpert, G. and Cathcart, R. (1985). Media grammars, generations, and media gaps. Critical Studies in Mass Communication, 2, 23-35.

Herman, Edward S., and Chomsky, Noam (1988). Manufacturing Consent: the political economy of the mass media. New York: Pantheon Books.

Hodgson, Godfrey (2000). The End of the Grand narrative and the Death of News. Historical Journal of Film, Radio and Television, March; v20, p. 23.

Johnson, Steven (1997). Interface culture: how new technology transforms the way we create and communicate. San Francisco: Harper Edge.

Innis, Harold (1951). The Bias of communication. Toronto: University of Toronto Press.

Lanham, Richard A. (1993). The Electronic World. Chicago.

MacDougall, R.C. (2001). Electronic Mail at a Mohawk Indian Community: an investigation into meaning and use. Ann Arbor: UMI.

McLuhan, M. (1962). The Gutenberg galaxy. Toronto: University of Toronto Press. 
McLuhan, M. (1964). Understanding media: The extensions of man. New York: McGraw Hill.

McLuhan, M., and Fiore, Q. (1967). The medium is the massage: An inventory of effects. New York: Bantam Books.

McManus, J.H. (1994). Market-Driven Journalism: let the citizen beware? Thousand Oaks, CA. Sage.

Meyrowitz, J. (1985). No sense of place: The impact of electronic media on social behavior. New York: Oxford University Press.

Mime, Chaelon, I.O. (2003). Conversations with at Brandeis University Neurophysiology Laboratories.

Mitroff, Ian A., and Bennis, Warren (1989). The Unreality Industry: the deliberate manufacturing of falsehood and what it is doing to your lives. New York: Oxford University Press.

Negroponte, Nicholas (1995). Being Digital. Boston, MIT Press.

Ong, W. J. (1982). Orality and literacy: The technologizing of the word. London: Routledge.

Postman, N. (1985). Amusing ourselves to death: Public discourse in the age of show business. New York: Penguin.

Postman, N. (1992). Technopoly: The surrender of culture to technology. New York: Alfred A. Knopf.

Schudson, Michael (2003). The New Journalism. In Communication in History: technology, culture, society, David Crowley and Paul Heyer, eds. Boston: Allyn and Bacon (pp. 138-45).

Shapiro, Andrew (1992). We're Number One: Where America Stands - and Falls - in the New World Order. New York: Vintage Books.

Stephens, Mitchell (1998). The Rise of the Image the Fall of the Word. New York. Oxford University Press.

Sundar, S. Shyam (1999). Exploring Receivers' Criteria for Perception of Print and Online News. In Journalism and Mass Communication Quarterly. Summer. Vol. 76; 2; pp. 373-386.

Tuchman, G. (1978). Making News: a study in the construction of reality. New York: Free Press.

Webster, J.G. and Phelan, P.F. (1997). The mass audience: Rediscovering the dominant model. Mahwah, NJ: Lawrence Erlbaum.

Zajonc, Robert (1984). On the Primacy of Affect. In American Psychologist. February, Vol. 39; pp. 117-23.

\section{Biography}

Robert MacDougall's general research interests center upon the social, political and psychological roles communication media have played throughout history. He is presently researching and writing about the widespread and very progressive use of the Internet as a newsgathering apparatus. A recent journal article considers the use and interpretation of e-mail by a group of Mohawk Indians. Dr. MacDougall has also written several journal articles and book chapters dealing with the rhetoric of science. His teaching history includes work at the State University of New York at Albany and Allegheny College in Western Pennsylvania.

\section{Appendix: Knowledge Quiz (v2.1)}

\section{Who is/are/was?}

Gerhardt Schroeder

Tony Blair

Jacques Chirac

Vicente Fox

Jean Chretien

Fidel Castro

Dick Cheney

Colin Powel
Condoleezza Rice

The Zapatistas

Nelson Mandela

Ted Turner

Rupert Murdoch

Jack Welch

Michael Eisner

Bill Gates

Andy Grove

Your Mayor
One of your Congress wo/men Your Senator

\section{What is/was?}

GATT

NAFTA

The IRA

The Hague

A ULEV

The Taliban 
Information, Interactivity, and the Prospects of a Global Citizenry

$\begin{array}{lll}\text { Al Qeida } & \text { Where is? } & \text { The Gaza Strip } \\ \text { A "Hybrid" } & \text { The District of Columbia } & \text { Kyoto } \\ \text { OPEC } & \text { East Timor } & \text { The Urals } \\ \text { The Euro } & \text { The Hague } & \text { The Sea of Tranquility } \\ \text { Beta Max } & \text { Rowanda } & \\ \text { The ingredients in a Big Mac? } & \text { Quebec }\end{array}$

